\title{
ELEMENTOS PARA A FORMULAÇÃO DE DIRETRIZES CURRICULARES PARA CURSOS DE PEDAGOGIA
}

\author{
MARIA AMÉLIA SANTORO FRANCO \\ Coordenação do Curso de Mestrado em Educação \\ da Universidade Católica de Santos \\ ameliasantoro@uol.com.br \\ JO SÉ CARLOS LIBÂNEO \\ Departamento de Educação da Universidade Católica de Goiás \\ libaneojc@uol.com.br
}

SELMA GARRID O PIMENTA

Faculdade de Educação da Universidade de São Paulo

sgpiment@usp.br

\section{RESUMO}

O debate nacional em torno do sistema de formação profissional de educadores, dos dispositivos legais e das diretrizes curriculares continua em aberto. A recente homologação da Resolução do Conselho Nacional de Educação - CNE - sobre as diretrizes curriculares nacionais para os Cursos de Pedagogia trouxe mais problemas que soluçôes. Leis e dispositivos normativos, pela sua natureza, cumprem a tarefa de ordenar ações e formas de funcionamento de instituições considerando necessidades e demandas da realidade; baseiam-se, no entanto, em saberes teóricos e práticos constituídos, decorrentes da reflexão, do estudo e da investigação. Este artigo discute esses elementos teóricos e práticos que devem figurar como pressupostos para emissão das leis, regulamentos e diretrizes que se proponham a normatizar questões educacionais, especificamente, questões de organização curricular de cursos de formação de educadores. Adicionalmente, submete a recente Resolução do CNE à crítica em face dos elementos assinalados.

FORMAÇÃO DE PROFESSORES - PEDAGOGIA - SISTEMA DE EDUCAÇÃO LEGISLAÇAO DE ENSINO

\section{ABSTRACT}

ELEMENTS FOR THE FORMULATION OF PEDAGOGY COURSE CURRICULAR GUIDELINES. The national debate around the educators' professional training system, the legal provisions and the curricular guidelines remains open. The recent homologation of the Resolution of the National Council of Education - CNE-about the national curricular guidelines 
for the Pedagogy courses brought about more problems than solutions. Laws and regulatory provisions, by their nature, fulfill the task of ordering actions and functioning ways of institutions taking into account real-world demands and necessities; however, they are based on established theoretical and practical knowledge, resulting from reflection, study and investigation. This article discusses these theoretical and practical elements which must function as assumptions for the issuance of laws, rules and guidelines that are meant to regulate educational issues, specifically, curricular organization issues of educators' training courses. Besides that, it puts the recent $C N E$ resolution under criticism in view of the elements pointed out.

TEACHER EDUCATION - PEDAGOGY - EDUCATION SYSTEMS - EDUCATIONAL LEGISLATION

\section{OS SENTIDOS DA PEDAGO GIA}

A Pedagogia, que do ponto de vista etimológico significa arte de condução de crianças, tornou-se durante muito tempo arte e doutrina da educação, até se consolidar como disciplina na universidade no final do século XVIII, graças, em boa parte, à contribuição de Herbart. A questão de saber o percurso pelo qual ela salta de uma arte para uma ciência é embaraçosa, em razão da sistemática polarização entre seu desígnio de teoria da ação educativa e sua vocação notoriamente prática. Não é casual que, em vários países e em diferentes tradições culturais, a Pedagogia se reporte ora à teoria da educação, ora a ações orientadoras para o ensino. Com Herbart, em sua obra Pedagogía geral de 1806 (ver Herbart, 2003), a Pedagogia adquire o estatuto de ciência uma vez que, no contexto da investigação filosófica de sua época, passa a assentarse em dois pilares, a Psicologia e a Ética, iniciando a abordagem epistemológica nesse campo teórico.

A Pedagogia compreensiva, originada no historicismo pela formulação inicial de Dilthey, situa o saber pedagógico entre as ciências do espírito, em que a educação tem um caráter eminentemente formativo, de cultivo interior e enriquecimento cultural. A partir da Sociologia positivista, Durkheim dedicou algumas obras bastante respeitadas à Pedagogia, como por exemplo, Educação e sociologia, de 1903 (ver Durkheim, 1985), pondo em destaque o papel da sociedade nos processos educativos. A educação é uma arte mas, também, uma ciência que deve gerar uma teoria prática para nortear a ação do educador.

A Pedagogia científica experimental, desenvolvida especialmente na França na segunda metade do século XIX, baseada em boa parte na Psicologia, 
restringe a investigação da educação àqueles problemas que podem ser tratados com métodos empírico-racionais, retraindo a reflexão em torno da autonomia da Pedagogia.

O movimento iniciado com as "escolas novas" e seu caráter ativista e individualista, entre o final do século XIX e início do século $X X$ inaugura uma efetiva virada no modo de pensar e praticar a educação e o ensino, repercutindo até hoje na experiência de investigadores e educadores. Esse vigoroso movimento, ao mesmo tempo que fortalece o interesse da sociedade pela educação, desenvolve a experimentação escolar com o primado do "fazer" e do papel do ambiente escolar, o que, de certa forma, desconecta a teorização pedagógica, acusada de demasiadamente prescritiva, em favor das ações diretamente ligadas à aprendizagem das crianças e à organização do espaço escolar. A proposta mais duradoura do movimento da educação nova foi formulada e difundida por John Dewey. É provavelmente uma das teorias de educação mais influentes no Brasil e também, a mais avessa em assumir a Pedagogia como ciência.

Entretanto, no mesmo período histórico, nas primeiras décadas no século $X X$, surge outro entendimento de uma nova educação, nascido do marxismo. Também baseada na atividade do ser humano, essa concepção ressaltou, para além da formação do indivíduo, o caráter político-social da educação, na perspectiva da emancipação, da igualdade, da transformação social, reafirmando uma concepção orgânica da ciência pedagógica.

percurso dos embates que, ao longo da história da educação brasileira, ora enaltecem ora recusam a especificidade da ciência pedagógica, tem sido objeto de investigação de vários autores, entre eles Libâneo (1997), Libâneo e Pimenta (1999) e Franco (2003). O que vimos mostrando até aqui é que, a despeito da discussão do conceito de ciência e de sua aplicabilidade ainda presente no âmbito das ciências humanas e da ojeriza de muitos intelectuais das ciências sociais à pretensão de cientificidade da Pedagogia, a investigação científica do fenômeno educativo tem uma tradição teórica respeitável, da qual dão mostras qualificados manuais de História da Educação (por exemplo, Visalberghi, 1983; Luzuriaga, 197I; Manacorda, 1989; Cambi, 1999).

$\bigcirc$ debate internacional sobre a questão mostra posições bastante distintas e, também, freqüentemente conflitivas. Seriam auspiciosos estudos comparados que nos permitissem saber o estado da discussão em países europeus, 
da América no Norte e do Sul. Atualmente a literatura que nos chega sobre o tema vem, sobretudo, da França, do Canadá, da Austrália e um pouco dos Estados Unidos. No Brasil, as discussões têm tido bastante ressonância, mesmo com o risco de adoção precipitada de posições teóricas ou de transposição acrítica de modelos. Um dilema que salta aos olhos em relação à trajetória dos estudos sobre a Pedagogia é aquele entre o seu sentido amplo e o sentido estrito, o primeiro como teoria da educação e da formação, o segundo como normas e orientações para o ensino. A tradição no pensamento pedagógico, principalmente o europeu, admite os dois sentidos, embora tenha predominado o sentido amplo, mais próximo da teoria da educação. No Brasil, durante algum tempo, os dois sentidos andaram em paralelo, mas, a partir dos anos 1920, com a penetração do ideário da escola nova, prevaleceu o segundo sentido, que acabou por impregnar o entendimento dos legisladores e de boa parte dos educadores ligados aos cursos superiores de formação de educadores.

Para os propósitos deste artigo, afirma-se o sentido de Pedagogia como teoria e prática da educação, na acepção que, grosso modo, é tomada do pedagogo alemão, Schimied-Kowarzik, para quem a Pedagogia é a ciência da e para a educação. Segundo esse autor, a Pedagogia investiga teoricamente o fenômeno educativo, formula orientações para a prática com base na própria ação prática e propõe princípios e normas relacionados aos fins e meios da educação. Ele expressa uma visão do papel formativo da Pedagogia em toda a sua complexidade:

A educação é uma função parcial integrante da produção e reprodução da vida social, que é determinada por meio da tarefa natural, e ao mesmo tempo cunhada socialmente, da regeneração de sujeitos humanos, sem os quais não existiria nenhuma práxis social. A história do progresso social é simultaneamente também um desenvolvimento dos indivíduos em suas capacidades espirituais e corporais e em suas relações mútuas. A sociedade depende tanto da formação e da evolução dos indivíduos que a constituem, quanto estes não podem se desenvolver fora das relações sociais. (1983, p.44)

É precisamente em razão da complexidade desses processos que a Pedagogia pode ser uma reflexão sistemática sobre as práticas educativas e para 
a ação educativa. Também o pedagogo francês Gaston Mialaret acentua a autonomia científica da Pedagogia, ao propor uma definição mais descritiva:

A Pedagogia é uma reflexão sobre as finalidades da educação e uma análise objetiva de suas condições de existência e de funcionamento. Ela está em relação direta com a prática educativa que constitui seu campo de reflexão e análise, sem, todavia, confundir-se com ela. (Mialaret, 1991, p.9)

O pedagogo espanhol Quintana Cabanas (1995), por sua vez, concebe a Pedagogia como a ciência da educação em geral, apresentando as linhas diretrizes a que se deve submeter a atividade educativa: fundamentos e fins da educação, o sujeito da educação, o educador e todos os tipos de educação. A existência da Pedagogia Geral, segundo esse autor, não substitui a teoria da educação, que seria o tratamento do fenômeno educativo em modalidades e situações concretas, envolvendo o conceito de educação e as formas de orientação do ato educativo. Beillerot escreve que a Pedagogia e, sobretudo a ação pedagógica, é

...por um lado, a imposição (...) de um sentido cultural arbitrário e, por outro lado, uma prática, ou seja, um conjunto de comportamentos e ações conscientes e voluntárias de transmissão de saberes (...), por explicações que apelam à razão de uma ou mais pessoas, com a finalidade de: (a) modificar os comportamentos, os afetos, as representações dos ensinados (...); (b) fazer e adquirir métodos e regras fixas que permitam fazer face a situações conhecidas que se reproduzem com regularidade; (c) fazer agir. (1985)

Tais posições remetem a um entendimento de Pedagogia como teoria e prática da educação, que estabelece finalidades e viabiliza processos organizativos, curriculares e docentes para as práticas educativas.

Essas relações da Pedagogia com a atividade prática do ensino fazem surgir diferentes sentidos para a atividade pedagógica. Se eles não forem bem especificados, podem redundar em apropriações inadequadas do termo. Durkheim, na obra citada (1985), identifica três sentidos para a noção de Pedagogia: como a arte do educador, como reflexão sobre a ação educativa e 
como doutrina educacional. Para o autor, a segunda concepção é a que mais esclarece o sentido da Pedagogia.

Em nossas publicações consideramos que o objeto da Pedagogia como ciência da educação é o esclarecimento reflexivo e transformador da práxis educativa. Nossa posição vai além do que estabelece Durkheim ao propor a Pedagogia como uma reflexão sobre as coisas da educação. Pensamos que a intencionalidade dessa reflexão é mais ampla, uma vez que o papel da Pedagogia será o de refletir para transformar, refletir para conhecer, para compreender, e, assim, construir possibilidades de mudança das práticas educativas. A ampliação da definição de Durkheim justifica-se, pois os estudos contemporâneos sobre a formação de professores demonstram que a prática docente é uma prática socioistórica que se organiza e se desenvolve mediante saberes próprios que a qualificam como uma capacidade que pode ser cientificamente desenvolvida e transformada. A docência passa a ser vista para além da arte. Consultar especialmente Pimenta (1999) Pimenta e Ghedin (2002), Libâneo e Pimenta (1999) e Libâneo (1998).

No entanto, a transformação das práticas só poderá ocorrer a partir da compreensão dos pressupostos teóricos que as organizam e das condições dadas historicamente. É também necessário considerar que a prática, como atividade socioistórica e intencional, precisa estar em constante processo de redirecionamento, com vistas a se assumir em sua responsabilidade social crítica. Esse papel político-crítico de pautar no coletivo as transformações da prática será desencadeado pela atividade pedagógica, em diferentes níveis de atuação. Com isso, a Pedagogia passa a ser a interlocutora interpretativa das teorias implícitas na práxis e também a mediadora de sua transformação para fins cada vez mais emancipatórios. A prática docente sem a presença "cientificizadora" da Pedagogia torna-se tecnologia do fazer.

Para tanto, cabe à tarefa pedagógica considerar que há arte na prática docente, mas será preciso transformar o artístico, o artesanal, o bom senso cotidiano, em atos científicos, sob a luz de valores educacionais, garantidos como relevantes socialmente, em uma comunidade social. A especificidade concreta da prática educativa se faz pelas ações artesanais, espontâneas, intuitivas, criativas, que se amalgamam, em cada momento de decisão, em ações refletidas, apoiadas em teorias pedagógicas, organizadas mediante críticas, autocríticas, expectativas de papel. Nesse sentido, no exercício da prática edu- 
cativa, convivem dimensões artísticas e científicas, expressas pela dinâmica entre o ser e o fazer; entre o pensar e o realizar; entre o poder e o querer realizar. A ação pedagógica amplia assim as possibilidades de autonomia das práticas docentes e se apropria de seu caráter peculiar de ação crítico-reflexiva, que Ihe foi tirado quando da emergência da cientificidade moderna, que impregnou o fazer educativo-pedagógico com estratégias que visavam um modo correto de fazer as coisas, ou que lhe foi suprimido mais tarde, na busca de competência técnica, distanciando dela sua possibilidade de produzir um processo contínuo de reflexão transformadora.

Uma decorrência também importante dessa consideração do pedagógico é fazer retornar aos professores e a todos os educadores o caráter de responsabilidade social da prática. Toda prática carrega uma intencionalidade, uma concepção de homem, de sociedade, de fins, sendo que estes precisam estar claros para os que exercem a prática educativo-pedagógica e para os que nela estão envolvidos, dentro de uma postura ética, essencial ao ato educativo. Sem a Pedagogia, permeando e dando sentido à prática docente, a ação docente transforma-se em mero modo de fazer uma tarefa.

Schmied-Kowarzik (1983) analisa a dialética da experiência da situação educacional como diretriz para a ação educativa. Ele diz que todo educador precisa reconhecer e dominar educacionalmente as situações educativas e suas exigências e afirma que capacitar o educador nesse sentido é a tarefa primeira das ações pedagógicas. Dominar as situações educativas não significa que o professor deva ser, apenas, treinado em habilidades e competências, como poderia pressupor a Pedagogia científica clássica. Dominar suas exigências não significa se submeter às exigências das circunstâncias, mas estar preparado para percebê-las e agir a partir delas. Dominar as situações educativas significa que o professor e o pedagogo, em tarefa coletiva, precisam criticamente avaliar e transformar os movimentos dialéticos da práxis.

Essas posições, de vários autores, ajudam a compreender os diferentes sentidos historicamente atribuídos à Pedagogia e que não a restringem a uma visão prescritiva e edificante em relação a propósitos formativos e nem apenas às práticas educativas voltadas ao ensino. No entanto, esses sentidos foram apropriados de diferentes maneiras, em diferentes espaços históricos, com diferentes intencionalidades, produzindo um mosaico de dimensões interpretativas sobre as práticas pedagógicas e tornando mais complexa sua epistemologia. $\bigcirc$ pesquisador ou o legislador, quando se referem à Pedagogia, esclarece- 
rem a dimensão interpretativa a que estão se reportando. Assim, Pedagogia passa a ser, na complexidade do mundo contemporâneo, quer um objeto de estudo, quer um conjunto de disciplinas formativas, quer um corpo teórico/prático de conhecimentos e saberes que se constituíram em seu fazer histórico.

Houssaye et al. (2002) vai mais longe ao analisar essas possibilidades, afirmando que a Pedagogia não deve ser considerada apenas um campo de estudos, um campo disciplinar, um objeto de práticas, uma qualidade de saberfazer, ou mesmo uma posição ideológica. Para ele, a Pedagogia é a reunião mútua e dialética da teoria e da prática educativa, em uma mesma pessoa, passando a considerar o pedagogo como aquele que procura conjugar a teoria e a prática pela própria ação, pressuposto que o faz afirmar: "só será considerado pedagogo aquele que fizer surgir um plus, na e pela articulação teoriaprática da educação" (2002, p. I0). A essa articulação em processo contínuo ele denomina "caldeirão da fabricação pedagógica". Concordamos com o autor e, se neste texto, são acentuadas algumas dimensões, separadas provisoriamente nos campos conceitual, disciplinar e de saberes, o fazemos para explicitar a inadequação da legislação referente às diretrizes curriculares, que não fundamentou nem definiu o campo conceitual da Pedagogia, fragmentou sua articulação disciplinar e desprezou os saberes historicamente construídos.

\section{DIMEN SÕ ESDE ABO RDAGEM DA PEDAGO GIA}

termo Pedagogia adquire diferentes conotações. Pode designar um determinado campo de conhecimento, numa dimensão epistemológica, ou um curso superior de formação de profissionais pedagogos, numa dimensão disciplinar, ou mesmo uma dimensão que congrega os fazeres práticos das ações educacionais cotidianas, cristalizados em procedimentos e modos de fazer. Compõe assim um arsenal teórico-prático, articulado entre saberes e fazeres da Pedagogia, numa dimensão que aqui chamaremos de prática (saberes pedagógicos). Há ainda outra dimensão, referente a um sistema teórico de intencionalidades educacionais, que se expressa nos ideais e propostas de diferentes pedagogos, a qual compõe o que se pode chamar de dimensão filosófica da Pedagogia, que não será abordada diretamente neste artigo.

A dimensão epistemológica constrói-se pela reflexão sobre o exercício das práticas e das intencionalidades que impregnam as ações pedagógicas co- 
tidianas, num processo contínuo de auto-esclarecimento, colocando a ação pedagógica sob a responsabilidade crítica. A dimensão prática constitui-se nesse campo de tensão entre o conhecimento educacional, os saberes da prática e as solicitações advindas das novas intencionalidades que se organizam no processo. A dimensão disciplinar se consolida por sua vez quase como uma síntese, com base nos saberes tornados inteligíveis pelo exercício da ciência pedagógica sobre as práticas, nos saberes teóricos constituídos na tradição investigativa e nas exigências postas pela sociedade em relação a propósitos formativos dos sujeitos. Essas dimensões, apesar de conectadas entre si, nem sempre estão em perfeita sintonia, já que procedem de diferentes lógicas, concebidas em tempos diversos e com diferentes intencionalidades. É sabido, por exemplo, que políticas curriculares acabam se atendo exclusivamente aos saberes práticos e desconhecendo a dimensão epistemológica de um campo científico, ou que saberes teóricos podem não se transformar, necessariamente, em saberes práticos ou mesmo em matérias de ensino.

Portanto quando se fala de Pedagogia, a que dimensão se está referindo? Ao longo dos últimos anos temos acompanhado as discussões, pesquisas e propostas para os cursos de Pedagogia, que resultaram na recente homologação das diretrizes curriculares para esses cursos'. Essas dimensões da Pedagogia foram contempladas no texto final das diretrizes? Sentem-se os pedagogos identificados e respaldados em suas práticas com esse texto legal normativo?

\section{Dimensão epistemológica}

A especificidade do campo científico e profissional da Pedagogia tem sido objeto de intensa polêmica nos meios intelectuais e profissionais ligados à educação. Todavia, boa parte das discussões no interior das faculdades de educação a partir dos anos 1980 tem sido prejudicada pela ausência dos próprios pedagogos que, devido à sua precária formação teórica, se deixaram substituir por filósofos, sociólogos ou psicólogos². Libâneo e Pimenta analisam essa dissonância dos estudos pedagógicos no país:

I. As diretrizes curriculares nacionais para o Curso de Pedagogia foram aprovadas pelo ConseIho Nacional de Educação, conforme Resolução n. I, de I 5 de maio de 2006.

2. Cumpre fazer justiça a publicações importantes sobre questões epistemológicas da Pedagogia, tais como Marques (1990), Pimenta (1997) e Franco (2003, 2005a), Libâneo (2005). 
A questão mais relevante (...) é o esvaziamento dos estudos sistemáticos de educação e a descaracterização profissional do pedagogo. (...) Por volta dos anos 1983-84, a partir da crítica à fragmentação e à divisão técnica do trabalho na escola, algumas Faculdades de Educação suprimiram do currículo as habilitações, passando a ter apenas duas habilitações - professor das séries iniciais do $1{ }^{\circ}$ grau e professor de cursos de habilitação ao magistério - descartando boa parte da fundamentação pedagógica do curso. Fora das faculdades, em decorrência dessas mudanças curriculares e da difusão das propostas do movimento pela reformulação da formação do educador, as Secretarias de Educação retiraram das escolas ou deixaram de contratar profissionais pedagogos, prejudicando o atendimento pedagógico-didático às escolas e comprometendo o exercício profissional do pedagogo. Além disso, com a descaracterização dos pedagogos-especialistas como profissionais, as associações de pedagogos (por exemplo, Associação Nacional de Orientadores Educacionais, Associação Nacional de Supervisores Educacionais) se auto-eliminaram, resultando na perda do espaço de discussão teórico-prática da Pedagogia e do exercício profissional do pedagogo então existente nessas associações. [...]

Essa análise mostra como se chegou a uma descentralidade do enfoque da Pedagogia como estudo da ciência da educação. (...) Na verdade, desde os anos 20, com o movimento da Educação Nova, os estudos pedagógicos sistemáticos começaram a perder espaço, a partir de operacionalização metodológica do ensino, a partir do que se propõe a formação dos técnicos de educação, com a segunda, a formação de professores, consolidando o privilegiamento das dimensões metodológica e organizacional em detrimento das dimensões filosófica, epistemológica e científica. (1999, p. 246)

Essas são as razões pelas quais a discussão sobre o campo científico e profissional da Pedagogia tem levado à sua desqualificação como campo de saberes específicos, principalmente quando o curso, com o mesmo nome, após homologação das atuais diretrizes, passou a ser identificado apenas como curso de preparação para a docência nas séries iniciais do ensino fundamental.

Essa situação dissonante, que identifica o campo de estudos pedagógicos como espaço exclusivo da docência para séries iniciais, demonstra a desarticulação entre as diferentes dimensões da abordagem da Pedagogia a que 
nos referimos. Epistemologicamente, a Pedagogia passa a ser tratada como metodologia; disciplinarmente, o curso de Pedagogia esvazia-se de conteúdos de consolidação teórica, e, quanto aos saberes práticos do exercício educativo, devido a intenções não explícitas, reduzem-se a rudimentos metodológicos e procedimentais.

Entretanto, paradoxalmente, o discurso da Pedagogia está em alta nos meios políticos, empresariais, profissionais, comunicacionais e em movimentos da sociedade civil. Observa-se expressiva movimentação na sociedade, mostrando uma ampliação do campo do educativo com a conseqüente repercussão na busca de novas formas de ação pedagógica. Não é casual, pois, que entre outras expressões que buscam identificar a sociedade atual, uma delas seja a de sociedade pedagógica conforme Beillerot (1985). Evidências de práticas pedagógicas aparecem nas mídias e em outros meios de comunicação, em que se veiculam diariamente mensagens educativas em vinhetas e chamadas sobre educação ambiental, Aids, drogas, saúde; na produção de material informativo tais como livros didáticos e paradidáticos, enciclopédias, guias de turismo, vídeos, revistas, jogos, brinquedos; na esfera dos serviços públicos estatais e em movimentos sociais, em que se disseminam várias práticas pedagógicas de assistentes sociais, agentes de saúde, agentes de promoção social nas comunidades; em programas sociais de medicina preventiva, informação sanitária, orientação sexual, recreação. Também ocorrem práticas tipicamente pedagógicas nas academias de educação física, nos consultórios clínicos, assim como nos presídios, hospitais e nas empresas. Desenvolvem-se em toda parte iniciativas de formação continuada, por meio de congressos, simpósios, seminários e demais encontros de profissionais.

Verifica-se, assim, uma ação pedagógica múltipla, em que o pedagógico perpassa toda a sociedade, extrapolando o âmbito escolar formal para abranger esferas mais amplas da educação informal e não formal, criar formas de educação paralela, desfazer praticamente todas as fronteiras que separavam escola, sociedade, cultura, economia. No entanto, é estranho que essa demanda de uma reavaliação das formas convencionais do aprender; da interseção do ensino e dos meios de comunicação e informação, do desenvolvimento de competências comunicativas, capacidades criativas para análise de situações novas e cambiantes e da capacidade de pensar e agir com horizontes mais 
amplos, ocorra fora do campo educacional específico, expressa por outros profissionais que não os pedagogos.

Por que essa situação tem se caracterizado dessa forma? Consideramos que a organização dos Cursos de Pedagogia tem-se realizado, historicamente, de forma cartorial, burocrática, desprezando a dimensão epistemológica que deveria fundamentá-los, e assim os profissionais pedagogos não conseguem ordenar sua profissionalidade com base na identidade que lhes é própria.

A não-consideração da natureza epistemológica da Pedagogia como campo científico da educação tem produzido dificuldades para a construção e compreensão da identidade profissional e para a formação do pedagogo. Apresentamos, resumidamente, cinco pressupostos que explicitam nossa posição sobre a epistemologia da Pedagogia e a formação de educadores.

Primeiro: A educação é uma prática social humana, cuja finalidade é possibilitar às pessoas se realizarem como seres humanos, portanto, partícipes do processo civilizatório, dos bens historicamente produzidos e dos problemas gerados por esse mesmo processo. Ela realiza essa finalidade pela mediação dos conhecimentos, da cultura, dos valores, dos modos de agir, por processos comunicacionais, implicando a apropriação e produção de saberes numa perspectiva crítica que tem por base o interesse emancipatório da sociedade.

Segundo: A Pedagogia, como ciência da educação, auxiliada por diferentes campos do conhecimento, estuda criticamente a educação como práxis social, visando analisá-la, compreendê-la, interpretá-la em sua complexidade e propor outros modos e processos para concretizá-la, com vistas à construção de uma sociedade justa e igualitária.

Terceiro: A Pedagogia é, antes de tudo, um campo científico, não um curso, campo esse cuja natureza constitutiva é a teoria e a prática da educação ou a teoria e prática da formação humana. O objeto próprio da ciência pedagógica é o fenômeno educativo, que compreende os processos de comunicação e internalização de saberes e modos de ação, visando à formação humana.

Quarto: Nesse sentido, a Pedagogia vincula-se diretamente à prática educativa, que constitui seu campo de reflexão, pesquisa e análise. Tem como tarefa o estudo e a reflexão sistemática sobre o fenômeno educativo, sobre as práticas educativas, o que a torna uma instância orientadora do trabalho pedagógico. É ciência da e para a educação, é portanto, a teoria e a prática da educação. Tem um caráter ao mesmo tempo explicativo, praxiológico e normati- 
vo da realidade educativa, pois investiga teoricamente o fenômeno da educação, formula orientações para a prática, mediante a própria ação, e propõe princípios e normas relacionados aos fins e meios da educação.

Quinto: A Pedagogia é um campo de conhecimento específico da prática social da educação, que se vale das demais áreas do conhecimento, quando essas se voltam para o estudo da educação. A estrutura básica de um curso de Pedagogia é o estudo do fenômeno educativo, em sua complexidade, e amplitude.

Nesse sentido e com base na natureza epistemológica da Pedagogia, reafirmamos que a docência é uma das modalidades da atividade pedagógica, o que nos leva a realçar que todo trabalho docente é trabalho pedagógico, mas nem todo trabalho pedagógico é trabalho docente. Ou seja, acreditamos que a docência se faz pela Pedagogia e não consideramos correto afirmar que a Pedagogia se faça pela docência. A inversão requerida não é meramente formal, ela expressa a articulação entre as três dimensões da Pedagogia que analisamos: a epistemológica, a disciplinar e a prática.

Afirmada a especificidade da Pedagogia como campo científico dedicado ao estudo da educação, é preciso encarar a questão da diversidade de enfoques do fenômeno educativo. Não há como negar a pluridimensionalidade do fato educativo, o que leva a admitir a necessidade de se recorrer a um conjunto de saberes para compreendê-lo e explicá-lo. Permanece, todavia, a polêmica: a Pedagogia é a única ciência da educação? Seria ela uma das ciências da educação? Ou não existe um campo científico chamado "Pedagogia", mas "ciências da educação?".

Consideremos alguns posicionamentos surgidos ao longo da história a respeito do estudo científico da educação e das possibilidades de organização do conhecimento pedagógico. Parece haver, efetivamente, quatro posições em relação a essa questão: Pedagogia, única ciência da educação, isto é, a Pedagogia geral; ciência da educação (em que desaparece o termo "Pedagogia"); ciências da educação (excluindo a Pedagogia); ciências da educação (incluindo a Pedagogia).

A primeira posição, mais tradicional, defende a unicidade da ciência pedagógica, ou seja, a Pedagogia seria a única ciência da educação; as demais ciências são chamadas "auxiliares". A denominação Pedagogia geral corresponde à concepção dos pedagogos clássicos alemães, a partir de Herbart, o primeiro 
defensor da autonomia da Pedagogia, tendo também exercido considerável influência na Pedagogia católica, que aparece, por exemplo, na obra de um dos mais importantes pedagogos católicos, Otto Willmann (1970). Essa posição tem recebido muitas críticas ao longo dos anos, por pretender exclusividade no tratamento científico da educação. Na verdade, o avanço das ciências humanas e sociais tem levado a considerar a realidade educativa como pluridimensional, tornando-se impróprio destacar uma disciplina que postule tal exclusividade.

A segunda posição não adota o termo Pedagogia, designando o estudo científico da educação como "ciência da educação" no singular, num enfoque positivista de ciência, bastante impregnado da idéia de experimentação educacional, por um lado, e da tecnologia educacional, por outro. No primeiro caso, o uso dessa denominação indica a aplicação ao campo educativo de princípios científicos incorporados de outras ciências, como podem ser caracterizadas a tradição da psicologia experimental francesa e a concepção de Dewey (1968). No segundo caso, a ciência da educação é o suporte científico da tecnologia educacional, isto é, aplicação das teorias de aprendizagem comportamentalistas e sistêmicas à prática de ensino, concepção de larga aceitação em países sob influência norte-americana (por exemplo, Von Cube, 198I). Em ambas as correntes, a visão cientificista do fenômeno educativo dilui o caráter ético-normativo associado ao termo Pedagogia, precisamente porque valores e fins da educação não podem ser inferidos cientificamente. Daí falar-se em ciência da educação e não em Pedagogia. Entendemos não ser casual que nos países anglo-saxões se empregue o termo educação para designar o que, em outros lugares, se conhece como Pedagogia.

A terceira posição adota a denominação "ciências da educação", bastante difundida em vários países, como França, Itália, Portugal, e com alguma repercussão em instituições universitárias brasileiras. A educação é objeto de estudo de um conjunto de ciências e, em alguns lugares, desaparece o campo de conhecimento conhecido por Pedagogia, embora não seja essa uma posição unânime. Mialaret (1976) autor francês de renome e um dos principais articuladores dessa tendência, informa que as "ciências da educação" em substituição aos estudos sistemáticos de Pedagogia, foram introduzidas nas universidades francesas em 1967. É bem possível que a redução do interesse acadêmico pelos estudos pedagógicos seja explicada pela grande difusão dessas 
idéias em vários países europeus, iniciando-se na França ${ }^{3}$. De fato, a diluição das dimensões do fenômeno educativo em vários campos, produz a dispersão do estudo da problemática educativa, levando a uma postura pluridisciplinar invés de interdisciplinar. Ou seja, a autonomia conferida a cada uma das ciências da educação leva a enfoques parciais da realidade educativa, comprometendo a unidade temática e abrindo espaço para os vários reducionismos (sociológico, psicológico, econômico...), como, aliás, a experiência brasileira tem confirmado ${ }^{4}$.

A quarta posição adere à denominação "ciências da educação", em que cada uma toma o fenômeno educativo sob um ponto de vista específico, mantendo-se, todavia, a Pedagogia como uma dessas ciências. Conforme esse ponto de vista, a pluridimensionalidade do fenômeno educativo não elimina sua unicidade, o que permite "estabelecer um corpo científico que tem o fenômeno educativo em seu conjunto como objeto de estudo, com a finalidade expressa de dar coerência à multiplicidade de ações parcializadas" (Sarramona, Marques, 1985, p.56). Nessa concepção, a Pedagogia promove uma síntese integradora dos diferentes processos analíticos que correspondem a cada uma das ciências da educação em seu objeto específico de estudo. Ou ainda, a Pedagogia apóia-se nas ciências da educação sem perder sua autonomia epistemológica e sem reduzir-se a uma ou outra, ou ao conjunto dessas ciências.

A última posição é a que adotamos por assegurar o caráter multidimensional e interdisciplinar do fenômeno educativo sem descartar o caráter peculiar da Pedagogia e da tradição de seus estudos. Autores de vários países ten-

3. Quintanas Cabanas lamenta a substituição do nome Pedagogia por ciências da educação nos anos 70, mencionando "uma triste iniciativa que acometeu o mundo pedagógico", ainda que seus criadores tenham acreditado que a nova expressão seria mais compatível com o caráter científico dos estudos da educação. Na verdade, segundo o autor, a expressão "ciências da educação" não eqüivale à expressão "Pedagogia" , tais ciências não a substituem (1995, p. I I).

4. O próprio Mialaret reconhece esse risco ao comentar o desenvolvimento desigual e separado entre os domínios das ciências da educação: "basta que uma obra importante ou original marque um dos domínios para que, no espírito de muitos dos nossos contemporâneos, as ciências da educação sejam identificadas com esse domínio" ( 1976, 9I). No caso brasileiro, não se trata de um risco, mas de uma realidade, pois são notórios todos os tipos de reducionismos: filosófico, sociológico, psicológico. Quintanas Cabanas, criticando a denominação "ciências da educação", escreve que não é certo que a "soma" das partes equivalha ao todo, necessitando um campo científico que faça uma integração compreensiva dessas partes (1995, p. 25). 
dem a aderir a essa posição. $\bigcirc$ italiano Visalberghi ( 1983) adota a expressão ciências da educação, mas denomina Pedagogia e ciências da educação o livro que publicou para indicar que "o seu eixo é o exame da relação entre os dois termos, não somente numa dimensão histórica, mas também, de um ponto de vista funcional atual pelo qual é bem legítimo falar ainda de Pedagogia para indicar a aproximação mais geral e intencionalmente voltada aos problemas educativos". Sarramona e Marques advogam o papel da Pedagogia na pluralidade das ciências da educação:

Advirta-se que a polifacética dimensão do fenômeno educativo não pode eliminar sua unicidade enquanto tal, sob o risco de perder sua justificação como processo objeto de estudo científico. Tal unicidade permite estabelecer um corpo científico que tome o fenômeno educativo em seu conjunto como objeto de estudo, com a finalidade expressa de dar coerência à multiplicidade de ações parcializadas; trata-se, em suma, de elaborar urna síntese integradora dos diferentes processos analíticos que correspondem a cada uma das ciências da educação, em seu objeto - dimensão da educação - específico de estudo. (1985, p.56)

O educador português Estrela é bastante explícito quanto aos equívocos produzidos pela expressão ciências da educação, seja pela falta de elucidação da problemática que a expressão envolve, seja por sua vulgarização como substituto do termo Pedagogia. Após reconhecer as dificuldades da Pedagogia para alcançar um autêntico estatuto científico, afirma:

A necessidade de cientificação tem levado o interventor pedagógico a recorrer a conceitos e a métodos das ciências já constituídas, que poderão ter aplicação no seu campo específico, o da Educação. A Psicologia, a Psicanálise, a Sociologia, a Psicossociologia, a Economia têm representado as principais ciências de recurso. Normalmente seus diagnósticos são seguros, as hipóteses emitidas são fecundas. No entanto, seu valor para o professor ou para o investigador pedagógico é, quase sempre, diminuto ou mesmo nulo. Constituem análises paralelas à problemática que lhes é específica. Na verdade, quando o psicólogo trabaIha no campo educacional, não faz (nem pode fazer) Pedagogia: aplica conceitos 
e métodos de sua ciência a um dos diversos campos da atividade humana, o da Educação. Os resultados são, pois, de ordem psicológica, como o seriam se o psicólogo exercesse sua ação no campo do trabalho, da clínica ou outro. 0 mesmo, evidentemente, se poderá dizer de outras ciências. (1992, p. I2)

Em síntese, esses posicionamentos mostram que foi apressada a atitude de postular a eliminação da Pedagogia como campo de conhecimento teórico com relativa autonomia epistemológica por parte de alguns intelectuais. Mesmo autores que aderem à denominação "ciências da educação" são unânimes em reconhecer no seio delas um âmbito propriamente pedagógico como núcleo científico medular no tratamento do fenômeno educativo.

Essa afirmação não leva a concluir que a Pedagogia ocuparia lugar hierarquicamente superior às demais ciências da educação. A Pedagogia não é, certamente, a única área científica que tem a educação como objeto de estudo. Também a Sociologia, a Psicologia, a Economia, a Lingüística, podem ocupar-se de problemas educativos para além de seus próprios objetos de investigação e, nessa medida, os resultados de seus estudos são imprescindíveis para a compreensão do educativo. Entretanto, cada uma dessas ciências aborda o fenômeno educativo sob a perspectiva de seus próprios conceitos e métodos de investigação. É a Pedagogia que pode requerer para si a investigação do campo educativo propriamente dito, como também de seus desdobramentos práticos, e com isso constituir-se em conhecimento integrador dos aportes das demais áreas.

A Pedagogia, assim considerada, é um campo de estudos com identidade e problemáticas próprias. Compreende os elementos da ação educativa e sua contextualização, tais como, o aluno como sujeito do processo de socialização e aprendizagem; os agentes de formação (inclusive a escola e o professor); as situações concretas em que ocorrem os processos formativos (inclusive o ensino); o saber como objeto de transmissão/assimilação); o contexto socioinstitucional das instituições (inclusive as escolas e salas de aula). Resumidamente, o objetivo do pedagógico se configura na relação entre os elementos da prática educativa: o sujeito que se educa, o educador, o saber e os contextos em que ocorre a educação.

Consideramos que o espaço de constituição da ciência da educação está vinculado à história das culturas, das demandas educacionais de cada momen- 
to histórico, aliado a intencionalidades sociais e a projetos políticos específicos. Do ponto de vista da epistemologia, não há como ignorar sua complexidade, seu caráter pluriforme e suas diferentes e possíveis formas de constituição. A natureza de sua epistemologia, que a leva à necessária predisposição para absorver novos saberes de outras áreas ou ciências, precisa ser levada em conta sem negligenciar sua capacidade de auto-reflexão ao articular esses saberes e sem permitir que ela se distancie de sua inevitável pertinência ao contexto da práxis. Só assim, articulada como síntese provisória de um espaço tensional, que se organiza entre diferentes dimensões conceituais, que carregam diferentes lógicas de convivência com o real, é que a epistemologia da Pedagogia pode ser considerada.

\section{Dimensão prática: a Pedagogia como saberes}

Os conhecimentos educacionais constituídos nem sempre expressaram a realidade complexa do fenômeno educativo. As teorias educacionais, muitas vezes, não traduziram o sentido implícito das práticas cotidianas e assim, nem sempre, impregnaram de compreensão o saber fazer dos educadores, dificultando sua utilização como suporte enriquecedor das ações práticas educativas. Consideramos que essa configuração se estruturou pelas dissonâncias que historicamente marcaram os desencontros das três dimensões da Pedagogia.

Daí uma possível explicação para a grande distância que se estabeleceu entre a teoria e a prática educativa. Ou seja, os estudos científicos de cunho positivista sobre a educação ao se utilizarem de olhares e suportes científicos, característicos de outras ciências, separaram sujeito e objeto de pesquisa, desprezaram as subjetividades inerentes à ação humana, distanciaram os interesses entre pesquisadores e pesquisados, recortaram artificialmente o contexto da pesquisa deixando, portanto, de apreender o essencial dessas práticas, congelando interpretações fragmentadas e sem sentido. Essas interpretações, captadas de forma parcial pelo olhar redutor dos pressupostos da ciência clássica, retiraram da cena educativa o significado original de suas práticas, expresso e vivido pelos protagonistas, impedindo que os resultados do trabalho científico fossem percebidos pelos sujeitos como expressão de sua ação. Para Söetard (2004, p.5 I), "as ciências da educação continuam sendo construções teóricas que não conseguem encontrar a passagem para o real e instrumentar realmente a prática". 
Quando os sujeitos não constroem sentido, não conseguem realizar a apreensão cognitiva/emocional dos conhecimentos teorizados e, assim, não percebem a relação entre os conhecimentos teóricos e suas ações cotidianas.

A inadequação histórica dos suportes científicos em relação à Pedagogia produziu muita dificuldade na interpenetração da teoria e da prática educacionais, o que impediu a fertilização mútua entre os dois pólos da atividade educativa, reafirmando a esterilidade de muitas teorias e a inadequação de muitas práticas.

Ao considerar a fragmentação de saberes na formação de professores e as flutuações de sentido da Pedagogia como ciência que, ao restringir-se ao campo aplicado das demais ciências, perde seu significado de ciência prática da prática educacional, Houssaye ( 1995 ) sugere, como caminho de superação, que os educadores se empenhem em construir saberes pedagógicos com base em necessidades pedagógicas postas pelo real, para além dos esquemas apriorísticos das ciências da educação. $\bigcirc$ retorno à Pedagogia só ocorrerá se as ciências da educação deixarem de partir de diferentes saberes constituídos e começarem a tomar a prática dos profissionais como ponto de partida e de chegada. Portanto só há um caminho: reinventar os saberes pedagógicos baseando-se na prática social da educação.

Pimenta (1999) tem razão ao afirmar que os saberes sobre a educação e sobre a Pedagogia não geram os saberes pedagógicos. Estes só se constituem a partir da prática que os confronta e reelabora. Mas os práticos não os geram só com o saber da prática. As práticas pedagógicas se apresentam na educação com estatuto frágil, reduzindo-se a objetos de análise de diferentes perspectivas: histórica, psicológica, antropológica etc. É preciso conferir-lhes um estatuto epistemológico. A Pedagogia, integrando as três dimensões mencionadas, poderá ocupar-se das possibilidades de construção de teorias fundamentadas na prática, criando estratégias didáticas e investigativas com vistas a auxiliar na composição de possíveis saberes pedagógicos, os quais poderão servir de apoio para a compreensão e transformação das práticas mediante ações críticas, realizadas pelos próprios docentes.

Para responder à questão da possibilidade de se construir saberes pedagógicos é preciso que se esclareça a concepção subjacente de Pedagogia. Se a Pedagogia é considerada como tecnologia, só pode produzir conhecimentos referentes à técnica; se é considerada em seu viés metodológico, produzirá 
conhecimentos sobre métodos; se é concebida como ciência da e para a práxis educativa, poderá produzir conhecimentos que fundamentam a prática, delineados a partir dos saberes pedagógicos construídos pelos docentes.

A Pedagogia é pois o espaço dialético para a compreensão e a operacionalização das articulações entre a teoria e a prática educativa. Do mesmo modo que não basta à Pedagogia refletir ou teorizar sobre o ato pedagógico, também não é suficiente orientar ou, muito menos, prescrever ações práticas para a concretização das práticas educativas.

Tratada como tecnologia, a Pedagogia não pode produzir saberes, ela produz, ou melhor, reafirma e reproduz fazeres. Essa concepção da Pedagogia como tecnologia, muito arraigada entre docentes brasileiros, leva a considerar que os saberes pedagógicos devem ser receitas de como se dar aula, ou mesmo, a aceitar orientações prescritivas do fazer prático, compreensíveis mediante a racionalidade técnica, que menospreza o sujeito ativo, inquiridor e renovador de suas circunstâncias.

Franco (2006) considera que os saberes pedagógicos têm a ver com um sujeito que gradativamente assume uma posição política diante do compromisso de ser professor, engajando-se criticamente em suas circunstâncias, cercando e acercando-se de sua realidade existencial, transformando-a na direção de suas intencionalidades. Assim esse sujeito fará uso do necessário conhecimento didático, metodológico, cultural, servindo-se do aparato teórico-prático para construir em ação seus saberes disciplinares, didáticos, metodológicos. A capacidade de articular o aparato teórico-prático, a capacidade de mobilizá-lo na condição presente, a capacidade de organizar novos saberes a partir da prática, essas capacidades em conjunto, estruturam aquilo que chamamos saberes pedagógicos.

A Pedagogia como ciência precisa assimilar o papel de integrar e disponibilizar os saberes produzidos pelos práticos, promovendo a situação comunicativa proposta por Habermas, a partir de uma perspectiva emancipatória, ou seja, valorizando os saberes dos práticos, permitindo-Ihes criar e transformar o sentido de seu cotidiano. Para tanto, requer-se da Pedagogia como ciência, um caráter de auto-reflexão, que inclui sempre a crítica por princípio e a intersubjetividade como ponto de partida na compreensão da subjetividade, com a finalidade emancipar o sujeito da opressão da racionalidade burocrática dos sistemas escolares. 


\section{Dimensão disciplinar: a Pedagogia como curso}

curso de Pedagogia forma pedagogos. Pedagogo é o profissional que estuda o que se insere na práxis da educação na sociedade. Portanto, vale dizer que esse estudo somente pode ser realizado como pesquisa das manifestações educativas que ocorrem nas sociedades, incluindo o ensino. Para isso, são necessários os fundamentos de várias áreas do saber, inclusive daquelas que estudam o ensino. Sua inserção profissional será transformadora e propositiva se baseada nesses princípios, e ocorrerá nas instituições educativas existentes e a serem criadas, que não apenas na escola. É por meio do campo profissional, da profissão que se muda o mundo. Será mediante a inserção profissional, o trabalho coletivo, que criamos as condições para sobreviver e para nos constituir como seres humanos, o que contribui para que outros também se constituam como tal, encetando assim ações transformadoras da realidade.

Para ampliar as considerações sobre o campo dos profissionais professores e pedagogos, situaremos a importância que a pesquisa nas universidades tem atribuído à questão da profissionalização, da formação e da identidade docente. No início dos anos 1990, e um pouco antes, o enfoque sobre a profissão de professor foi acentuado ${ }^{5}$ com amplo investimento em pesquisas, que demonstraram o caráter ideológico da concepção de "missionário" que marca a profissão docente e a importância de valorizar os professores em sua formação, autonomia e condições de trabalho, como meio para melhorar a qualidade da escolarização. A profissionalização passa a ser entendida como identificação de uma categoria profissional que ultrapassa a dimensão meramente corporativa e que situa o sentido social da intervenção do professor como uma forma de transformação da sociedade.

As questões referentes à profissionalização docente revestem-se de grande importância, especialmente quando se trata dos professores das séries iniciais, tradicionalmente desqualificados social e profissionalmente, tal como o apelativo "tia" dá indícios. Por isso, trata-se efetivamente de uma conquista a elevação de sua formação para o nível superior, proposta na Lei de Diretrizes e Bases da Educação Nacional - LDBEN -, em que pesem as contradições des-

5. Sobre esses temas ver, por exemplo, Brzezinski (1996), Pimenta (1998), Guimarães (2004). 
sa lei, pois ensinar crianças é uma atividade tão complexa quanto o cuidado da saúde da criança pelo pediatra, formado em nível superior. Para a formação de professores nesse nível há as universidades e, nelas, o Curso de Pedagogia. Não seria, pois necessário inventar nova instituição, embora seja preciso reinventar o Curso de Pedagogia para dar conta também dessa formação.

Acreditamos que a base de um curso de Pedagogia não pode ser a docência. Como já afirmamos, todo trabalho docente é trabalho pedagógico, mas nem todo trabalho pedagógico é trabalho docente. A docência é uma modalidade de atividade pedagógica, de modo que a formação pedagógica é o suporte, a base, da docência, não o inverso. Ou seja, a abrangência da Pedagogia é maior que a da docência. Um professor é um pedagogo, mas nem todo pedagogo precisa ser professor. Isso de modo algum leva a secundarizar a docência, pois não estamos falando de prioridades de campos científicos ou de atividade profissional, estamos falando de uma epistemologia do conhecimento pedagógico.

Em face desse posicionamento, entendemos que a formação dos profissionais para atuar na educação básica e em outras instâncias de prática educativa deverá ser feita nas faculdades/centros de educação, que oferecerão curso de bacharelado em Pedagogia e curso de formação de professores. Compreendemos, que o objeto da legislação em pauta não poderia ter sido o curso de licenciatura para a formação de professores, mas o de graduação em Pedagogia, que se destina à formação de profissionais de educação não docentes, voltado para os estudos teóricos da Pedagogia, para a investigação científica e para o exercício profissional no sistema de ensino, nas escolas e em outras instituições educacionais, incluindo as não escolares.

Para nós, portanto, o curso de Pedagogia constitui o único curso de graduação cuja especificidade é proceder à análise crítica e contextualizada da educação e do ensino como práxis social, formando o profissional pedagogo, com formação teórica, científica, ética e técnica com vistas ao aprofundamento na teoria pedagógica, na pesquisa educacional e no exercício de atividades pedagógicas específicas. Deverá ser oferecido nas faculdades/centros de educação, em instituições universitárias, com duração mínima de 3.200 horas, num período mínimo de quatro anos.

○ currículo de formação do pedagogo deve assegurar a formação em pesquisa e o exercício de atividades educativas nas escolas e em espaços não 
escolares, tais como: sistemas escolares e escolas, incluindo universidades e instituições de ensino superior; movimentos sociais, organizações comunitárias; mídias, incluindo o campo editorial, vídeos, e outras tecnologias; áreas da saúde (projetos de prevenção, difusão científica para fins educativos etc.); empresas; sindicatos; instituições culturais, de lazer, de turismo para diversas faixas etárias, entre outros.

Em seu exercício profissional, o pedagogo estará habilitado a desempenhar atividades relativas à: formulação e gestão de políticas educacionais; formulação e avaliação de currículos e de políticas curriculares; organização e gestão de sistemas e de unidades escolares; coordenação, planejamento, execução e avaliação de programas e projetos educacionais, para diferentes faixas etárias (crianças, jovens, adultos, terceira idade); formulação e gestão de experiências educacionais; coordenação pedagógica e assessoria didática a professores e alunos em situações de ensino e aprendizagem; coordenação de atividades de estágios profissionais em ambientes diversos; formulação de políticas de avaliação e desenvolvimento de práticas avaliativas no âmbito institucional e nos processos de ensino e aprendizagem em vários contextos de formação; produção e difusão de conhecimento científico e tecnológico do campo educacional; formulação e coordenação de programas e processos de formação contínua e desenvolvimento profissional de professores em ambientes escolares e não escolares; produção e otimização de projetos destinados à educação a distância, programas televisivos, vídeos educativos; desenvolvimento cultural e artístico para várias faixas etárias. Em toda e qualquer inserção profissional e nas funções que exerça, o pedagogo, assim formado, estará em condições de articular as diversidades, as desigualdades culturais e sociais e as necessidades especiais dos seres humanos envolvidos no processo de educação.

A posição que assumimos torna explícita a integração das três dimensões de Pedagogia, ou seja, sua epistemologia fundada na tradição teórica e nos saberes da prática, funde-se com as condições históricas atuais, para fornecer os elementos de elaboração da legislação, particularmente das diretrizes curriculares nacionais para os cursos de Pedagogia. É esse caminho que poderia abrir espaços políticos e institucionais para a retirada do pedagogo do limbo profissional e identitário em que se encontra e de sua falsa e inconsistente identificação como professor. Com efeito, o esfacelamento dos estudos no âmbito 
da ciência pedagógica com a conseqüente subsunção do especialista ao docente e a improcedente identificação dos estudos pedagógicos com uma licenciatura, talvez sejam dois dos mais expressivos equívocos teóricos e operacionais da legislação e do próprio movimento de reformulação dos cursos de formação do educador, no que se refere à formação do pedagogo.

Sendo assim, como situar o curso de Pedagogia e seus profissionais? Como devem ser organizados, hoje, os cursos de Pedagogia no Brasil? A que desafios deverão responder? Em torno de que intencionalidades devem se organizar? As diretrizes que acabam de ser homologadas respondem a tais perspectivas?

Nas últimas décadas foram produzidos valiosos estudos que registram discussões críticas e debates sobre a reformulação dos cursos de Pedagogia, trazendo à tona questões sobre a complexidade da tarefa educativa, do fazer docente, da epistemologia das práticas educativas, das quais emergem reflexões sobre a identidade do professor, do pedagogo e dos cursos de formação. Como comenta Silva (1999), o Comitê Pró-Reformulação dos cursos de Pedagogia, em 1981, já se insurgia contra a concepção tecnicista que permeava a formação dos docentes e reforçava posicionamentos em direção à formação do professor como educador para qualquer nível de ensino. Os debates são amplos, nem sempre convergentes, mas carregam o intento de ampliar a discussão para setores cada vez mais abrangentes da comunidade educativa e de buscar meios para superar a opressão da racionalidade imposta pelos órgãos burocráticos do Ministério da Educação.

Cumpre assim realçar alguns pontos presentes no debate sobre os cursos de Pedagogia. Uma primeira observação é que a análise da história desses cursos demonstra que desde as origens até o momento atual, não se equacionou de forma satisfatória a questão de sua especificidade. Silva (1999), descreve esta situação em três fases: a da "identidade questionada", que corresponde ao período de 1939-1972, em que se questionam especialmente as funções atribuídas ao curso ao longo das sucessivas regulamentações legais; a da "identidade projetada", que vai de 1973 a 1978, período em que se especulou inclusive, sobre a extinção dos referidos cursos; a da "identidade em discussão", que se inicia na década de 1980 e está ainda em plena atividade, em decorrência das discussões produzidas a partir da nova LDB 9.394/96 e atos governamentais posteriores. Desta última, deve-se realçar o trabalho de diver- 
sos educadores que procuram fundamentar caminhos para a estruturação da Pedagogia como ciência voltada à prática educativa.

Outra observação é sobre as práticas educativas. Constata-se no país grande distância entre o discurso pedagógico progressista e as práticas educativas ainda bastante pautadas numa linha de trabalho técnico-científico, com algumas exceções importantes. As dificuldades com o fazer educativo cotidiano têm produzido numerosos estudos e discussões, sobre a questão da formação de professores, conforme podemos ver em Libâneo (2006) que se refere à relação entre as políticas educacionais e as necessidades e demandas concretas da escola.

Uma terceira observação diz respeito à impermeabilidade de muitos legisladores e intelectuais quanto à compreensão a especificidade da Pedagogia. Seria preciso levar em conta que as considerações em torno da natureza da educação e do seu campo teórico - a Pedagogia - resultam, do ponto de vista escolar, na projeção e materialização dos aspectos educacionais e culturais da sociedade num currículo. Não cabe neste texto entrar nas questões de organização curricular. Apenas se quer reafirmar que a Pedagogia, antes de se desdobrar em docência, constitui um campo de estudos com identidade e problemáticas próprias, englobando os elementos da ação educativa e sua contextualização.

Por fim, há que se considerar que a valorização de professores como profissionais, coloca a necessidade de refletir sobre o significado de se concluir um curso superior sem uma clara identidade profissional. É o que está acontecendo com os pedagogos. É preciso que os cursos assumam a responsabilidade de formar seus pedagogos, com condição legal de inserção no mundo social do trabalho, o que é muito diferente de formá-los para o mercado de trabalho, condição para que mudem as formas e os processos de oferecer a educação, o ensino, as políticas de educação de crianças, jovens e adultos, os processos educativos formais e não formais, a gestão do ensino e das escolas e de instituições educativas e outras demandas sociais. $\bigcirc$ avanço na área da formação de professores, colocando em pauta e apontando caminhos para a construção da identidade docente, dos saberes que o identificam, da profissionalização e da profissionalidade, da formação e das condições de inserção no mundo do trabalho, pode iluminar a área da Pedagogia no que se refere à profissionalização do pedagogo que, como afirmamos, não se pode resumir à docência das séries iniciais, nem com ela se identificar. 


\section{NECESSIDADES DA ESCO LA BRASILEIRA E DESAFIOSAO TRABALHO DOSPEDAGOGOS}

Convivemos na sociedade globalizada com mudanças na economia, no sistema de produção, na oferta de empregos. Há novos requisitos de qualificação profissional, novas formas de fazer política, de formação do cidadão. Do ponto de vista cultural, o mundo da informação, das mídias, modifica modos de vida individual e social de todos os segmentos sociais, mas especialmente da juventude. Também vivemos uma crise moral sem precedentes, em boa parte induzida pelo relativismo ético. $\bigcirc$ intenso processo de urbanização e o aumento da complexidade nas diferentes esferas da vida social ampliam as responsabilidades da escola, ao mesmo tempo que destacam o papel educativo da cidade. A democratização do acesso à escola, a industrialização, a migração interna, o êxodo rural, o inchamento das grandes cidades resultam na diversidade social e cultural dentro da escola, tornando heterogêneas as necessidades individuais e sociais a atender. Os influxos da sociedade da informação, em especial dos meios de comunicação, produzem mudanças comportamentais na juventude e afetam as formas de aprender. São desafios de um mundo em mudança que atingem diretamente as escolas e o trabalho dos professores.

No âmbito do sistema de ensino, sabemos que a escola brasileira suporta há anos problemas crônicos - a pobreza das famílias, o baixo salário dos professores, a desvalorização social da profissão docente, as precárias condições físicas e materiais das escolas, a repetência, a defasagem idade-série escolar, as dificuldades de aprendizagem dos alunos, fatores esses que contribuem para o rebaixamento da qualidade de ensino. Temos diagnósticos confiáveis mostrando o baixo rendimento da maioria das escolas de ensino fundamental. Constata-se que boa parte do professorado não tem domínio dos conteúdos e de métodos e técnicas de ensino, falta-lhes cultura geral de base, eles têm notórias dificuldades de leitura e produção de textos, estão despreparados para lidar com a diversidade social e cultural e com problemas típicos da realidade social de hoje como a violência, a influência das mídias, a indisciplina. São conhecidos também outros fatores que intervêm negativamente no trabalho da sala de aula como a desmotivação, a rotatividade, o absenteísmo e o estresse de professores. Acrescente-se ainda a fragilidade das formas de organização e gestão da escola, que tornam mais difíceis as ações efetivas com vistas a uma educação de qualidade. 
Verifica-se, assim, que os problemas da formação profissional de educadores no Brasil são institucionais, históricos, legais, mas resultam de uma problemática que está em outro lugar, ou seja, no mundo real e concreto das escolas situadas, por sua vez, em um mundo em mudança. Diante desses fatos, instituições formadoras, escolas, educadores, e pesquisadores se encontram perplexos, inseguros, em parte pela magnitude dos problemas, em parte pelo sentimento de incompetência para enfrentá-los.

A melhoria do ensino e do trabalho dos professores não depende somente da formação dos pedagogos-especialistas, mas estes podem proporcionar às escolas ajuda inestimável para pensar teoricamente e atuar quanto à definição de objetivos sociais e culturais para a escola, às capacidades a formar, às competências cognitivas e habilidades a desenvolver, aos formatos curriculares, às metodologias de ensino, às práticas de gestão, aos níveis esperados de desempenho escolar dos alunos.

São duas as perguntas básicas que os pedagogos precisam se fazer. A primeira é: - que tipo de sujeitos devem-se tornar as pessoas que educamos, de modo a se capacitarem a atuar de forma crítica e criativa na realidade em que vivem? A segunda é: - qual o caminho das ações individuais dos sujeitos para que aprendam a atuar de modo transformador numa realidade em mudança? A resposta a estas perguntas indicará o sentido de educar pessoas, de formar profissionais, de formular leis e diretrizes curriculares.

E o que é educar? Educar é intervir na capacidade de ser e de agir das pessoas. Para isso, são providas as mediações culturais, isto é, as ferramentas simbólicas e materiais, mediante um processo de comunicação. É disso que trata a Pedagogia: da mediação de saberes e modos de agir. $\bigcirc$ papel da Pedagogia é promover mudanças qualitativas no desenvolvimento e na aprendizagem das pessoas, visando ajudá-las a se constituírem como sujeitos, a melhorar sua capacidade de ação e as competências para viver e agir na sociedade e na comunidade.

São muitos os lugares e as modalidades de cumprimento dessa tarefa. De fato, o pedagogo é o profissional que cuida da formação humana em todos os lugares em que essa formação acontece de forma intencional e sistemática. Assim, todo profissional que lida com a formação de sujeitos, seja em instituições de ensino seja em outro lugar, é um pedagogo. Entretanto, na realidade brasileira, as instituições de ensino formal ganham destacada importância, ra- 
zão pela qual é crucial saber o que a Pedagogia pode fazer pelas escolas e pelos professores.

Conhecemos muito bem os componentes da aprendizagem escolar: o que deve ser aprendido, quais são os resultados esperados; como se aprende - em que se constitui os processos de aprendizagem; as condições do ensino e aprendizagem, ou seja, que tipos de práticas são necessárias para por em ação os processos de aprendizagem, onde, quando, com que recursos físicos e organizacionais etc.

O essencial da relação pedagógica é educar e ensinar por meio da relação professor-aluno-conteúdo, viabilizada por condições concretas. Em outras palavras, o básico da escola consiste em formar a personalidade dos alunos e lhes oferecer as ferramentas para o seu desenvolvimento cognitivo. Para isso, muitas condições precisam ser atendidas em relação aos níveis de desenvolvimento e aprendizagem dos alunos, à seleção e organização dos conteúdos, às formas de estimulação e motivação, ao espaço físico e ambiental, às formas de organização e gestão da escola e da sala de aula, aos instrumentos de avaliação da aprendizagem, aos meios de redução de dificuldades de aprendizagem etc.

A ciência pedagógica pautada em sua história e práxis, pode-se tornar, pois, instrumento para direcionar as principais demandas educacionais do país, quais sejam : qualificar a formação de docentes como um projeto políticoemancipatório; organizar o campo de conhecimento sobre a educação, na ótica do pedagógico; articular teoria educacional com prática educativa; transformar espaços potenciais educacionais em espaços educativos/formadores; qualificar o exercício da prática educativa com vistas a diminuir práticas alienantes, injustas, excludentes da escola e da sociedade e, assim, encaminhar a sociedade para processos cada vez mais humanizadores.

São essas as tarefas a serem assumidas pelas escolas e pelos professores, mas principalmente, são essas as tarefas da Pedagogia para as quais são imprescindíveis os professores. Porém, para empoderar a escola e os professores são necessários também os pedagogos especialistas com formação específica. Com isso, é a escola, a sala de aula e seu entorno sociocultural, que deve ser a referência para as políticas educacionais, a legislação, o funcionamento das instituições de ensino, os sindicatos, as associações etc. 


\section{O NDE FALHAM AS DIRETRIZES CURRICULARES}

O projeto de Resolução aprovado pelo CNE tem como objetivo instituir as diretrizes curriculares nacionais para os cursos de graduação em Pedagogia. Consideramos que o texto da resolução falha substancialmente por não ter considerado a articulação entre as dimensões epistemológica, disciplinar e prática da Pedagogia. Mais que isso, desprezou a epistemologia desse campo científico; desconsiderou as possibilidades e necessidades da formação do profissional pedagogo para atender às complexas demandas da escola brasileira e, ainda, não se apropriou dos saberes da prática pedagógica, construídos no seu caminhar histórico.

A insuficiência mais evidente, refere-se à falta de uma conceituação epistemológica clara de Pedagogia. $\bigcirc$ texto estabelece a que se destina o curso, as modalidades de formação, as competências do egresso, mas não explicita a natureza e o objeto do campo do conhecimento pedagógico. Sem definir previamente o que é a Pedagogia, introduz no artigo $2^{\circ}$ a conceituação de docência nos seguintes termos: "Compreende-se docência como ação educativa e processo pedagógico metódico e intencional, construído (sic) em relações sociais, étnico-raciais e produtivas, as quais influenciam conceitos e objetivos da Pedagogia" (Brasil, 2005).

Surgem daí perguntas embaraçosas. As referidas diretrizes não são para o curso de Pedagogia? Por que o campo a ser conceituado é o da docência? Pedagogo e professor são conceitos sinônimos? As funções desempenhadas pelo professor são as mesmas destinadas ao pedagogo? Historicamente, pedagogo e professor foram profissões idênticas? Formar alguém para ser professor requer as mesmas capacitações, as mesmas condições curriculares, que formar um pedagogo? Todo professor é pedagogo? Todo pedagogo é professor? $\bigcirc$ texto das diretrizes, ao subsumir a docência à Pedagogia peca na essencialidade do propósito formativo. $\bigcirc$ princípio deveria ter sido o esclarecimento teórico do conceito, a partir do qual seriam formuladas diretrizes e normas.

No entanto, em todo o texto da resolução, a única definição teórica de termos, é a mencionada conceituação de docência. Observe-se contudo que essa definição é insustentável do ponto de vista lógico, pois define o termo principal pelo secundário, ou seja, a docência, um conceito subordinado à Pedagogia, é identificado com sendo a própria Pedagogia. Ao postular essa iden- 
tificação, os legisladores desconhecem a tradição teórica e a estrutura lógicoconceitual da ciência pedagógica. Dessa insuficiência conceitual decorre a confusão elementar entre o campo científico e seu objeto, entre Pedagogia e docência, entre ação educativa e ação docente e, afinal, a redução do curso de Pedagogia ao curso de formação de professores.

As imprecisões conceituais não param aí. No mesmo artigo $2^{\circ}$ se afirma que "o curso de Pedagogia (...) propiciará o planejamento, execução e avaliação de atividades educativas" (grifo nosso). A Pedagogia, nessa frase, já não tem mais como objeto a docência, mas as atividades educativas. Afinal, qual é o conceito epistemológico de Pedagogia na resolução?

A insuficiência conceitual leva a definições operacionais muito pouco convincentes do ponto de vista teórico e o exemplo mais patente é a definição de atividades docentes tal como consta no parágrafo único do artigo $4^{\circ}$ :

As atividades docentes também compreendem participação na organização e gestão de sistemas e instituições de ensino, englobando:

I - planejamento, execução, coordenação, acompanhamento e avaliação de tarefas próprias do setor da Educação;

II - planejamento, execução, coordenação, acompanhamento e avaliação de projetos e experiências educativas não-escolares;

III - produção e difusão do conhecimento científico-tecnológico do campo educacional, em contextos escolares e não-escolares.

A imprecisão conceitual que salta aos olhos é o entendimento de que quaisquer atividades profissionais realizadas no campo da educação, ligadas à escola ou extra-escolares, são atividades docentes. Ou seja, o planejador da educação, o especialista em avaliação, o especialista em currículo, o animador cultural, o pesquisador, o editor de livros, todos os que estariam exercendo docência nessas atividades são docentes. Em suma, é patente a confusão que o texto provoca ao não diferenciar campos científicos, setores profissionais, áreas de atuação, ou seja, uma mínima divisão técnica do trabalho necessária em qualquer âmbito científico ou profissional sem o que a prática profissional pode tornar-se inconsistente e sem qualidade. Em boa parte, decorrentes dessas insuficiências de base, são verificadas outras falhas: 
- $\bigcirc$ texto das diretrizes, apesar de não usar a denominação "bacharelado", define a parte inicial do curso (eixo um) como "licenciatura" e determina que o outro eixo "será definido conforme os projetos de cada instituição". Isso na prática significa duas coisas: a. a identidade nacional do pedagogo passa a ser a de professor; b. o eixo dois tem grande chance de ser configurado como "habilitações" (bacharelado) conforme a realidade de cada lugar! E as duas coisas significam retrocesso e inadequação do texto.

- $\bigcirc$ artigo $5^{\circ}$ descreve as competências necessárias aos egressos do curso de Pedagogia, arrolando 16 atribuiç̧̃̃es do docente. São descrições em que se misturam objetivos, conteúdos, recomendações morais, gerando superposições e imprecisões quanto ao perfil do egresso.

- $\bigcirc$ artigo $2^{\circ}$, $\S 2^{\circ}$, e o artigo $3^{\circ}$ apresentam orientações desconexas sobre a formação, distintas ou sobrepostas às competências do pedagogo mencionadas do artigo 5.

- Nos artigos $2^{\circ}$ e $4^{\circ}$, que estão repetidos, são criadas cinco modalidades de magistério, a saber: educação infantil; anos iniciais do ensino fundamental; cursos de ensino médio na modalidade normal; cursos de educação profissional na área de serviços e apoio escolar; outras áreas que requerem conhecimentos pedagógicos. Das cinco modalidades formativas, há referência apenas a duas em todo o texto: educação infantil e anos iniciais. Faltam orientações quanto ao percurso curricular e às modalidades de diplomação. Não se esclarece se são percursos curriculares separados ou se há uma base comum que depois se ramifica em habilitações (o texto não menciona o termo "habilitações", nem outro equivalente). Do mesmo modo, o artigo que trata da formação dos profissionais da educação para administração, planejamento, supervisão etc. (artigo 64 da Lei n. 9.394/96) em nível de pós-graduação está inteiramente desconectado dos demais, deixando dúvidas aos dirigentes de cursos de formação. Além disso, a resolução ignora a prescrição legal da LDBEN de que essa formação deve ser feita também em cursos de graduação em Pedagogia.

- $\bigcirc$ artigo $6^{\circ}$ define a estrutura curricular em três blocos: núcleo de estudos básicos, núcleo de aprofundamento e diversificação de estu- 
dos, núcleo de estudos integradores, em que supostamente se incluem disciplinas e atividades curriculares, mas isto não está suficientemente claro devido à redação confusa e à imprecisão.

- $\bigcirc$ artigo 90 exclui toda e qualquer outra modalidade de formação inicial que não as estabelecidas na resolução. $\bigcirc$ artigo 10 determina a extinção de todas as habilitações em vigor; o artigo I 4 estabelece a formação de especialistas em cursos de pós-graduação; o artigo | | mantém o Curso Normal Superior.

Em conclusão, a Resolução do CNE expressa uma concepção simplista, reducionista, da Pedagogia e do exercício profissional do pedagogo, decorrente de precária fundamentação teórica, de imprecisões conceituais, de desconsideração dos vários âmbitos de atuação científica e profissional do campo educacional. Após 15 anos de discussões e polêmicas, a resolução não contribui para a unidade do sistema de formação, não avança no modo necessário de formação de educadores para a escola atual, não ajuda a elevar a qualidade dessa formação e, assim, afeta aspirações de elevação do nível científico e cultural dos alunos das escolas de ensino fundamental. É forçoso concluir que o documento normativo do CNE, que resultou em boa parte da assimilação de idéias e recomendações de uma associação de educadores, acabou por levar à manipulação pragmática do currículo de formação profissional.

Os cursos de Pedagogia e de formação de professores estão localizados nos mais distantes municípios e formam profissionais, compõem as culturas locais, criam um tipo de cidadão, ajudam as crianças a terem um rumo na vida, ampliando as possibilidades de conquistar a dignidade humana. Há algo de imensurável quanto aos benefícios sociais e humanos que provêm do trabalho dos professores em cada recanto do país, especialmente no ensino fundamental, portanto são necessários os pedagogos e os professores. Melhorando as escolas e melhorando a formação de professores se possibilita a elevação da qualidade cognitiva das aprendizagens dos alunos, com vistas a formar brasileiros mais cultos, cidadãos mais participantes dos benefícios materiais e culturais promovidos pelo desenvolvimento social e econômico. Todo educador que tem clareza do seu papel social e político sabe que a escolarização básica obrigatória tem um significado educativo, político e social que implica o direito de todos, em condições iguais de oportunidades, ao acesso aos bens culturais, ao 
desenvolvimento das capacidades individuais e sociais, à formação da cidadania, à conquista da dignidade humana e da liberdade intelectual e política.

É por tudo isso que se requer uma legislação clara, consistente e, ao mesmo tempo, aberta à complexidade e diversidade da realidade, para além das divergências acadêmicas e políticas. A educação brasileira continua carente dessa legislação. Consideramos que o Ministério da Educação deve reavaliar a pertinência de homologar a resolução que dispõe sobre as diretrizes curriculares para a Pedagogia porque não atende às necessidades sociais e pedagógicas de formação de educadores postas por um mundo em mudança. Sugerimos, também, que essa reavaliação busque fundamentar-se na articulação entre as dimensões epistemológica, prática e disciplinar, de forma a sustentar um diálogo com a realidade educacional, para potencializar a superação do campo tensional que tem produzido indesejadas rupturas entre as necessidades e as possibilidades da educação brasileira.

\section{REFERÊN CIAS BIBLIO GRÁFICAS}

BEILLEROT, J. A Sociedade pedagógica. Porto: Rés, 1985.

BRASIL. Conselho Nacional de Educação. Projeto de Resolução do CNE. Brasília, 2005.

CAMBI, F. História da pedagogia. São Paulo: Editora Unesp, 1999

DEWEY, J. La Ciencia de la educación. Buenos Aires: Losada, 1968.

DURKHEIM, E. Éducation et sociologie. Paris: PUF, 1985.

ESTRELA, A. Pedagogia, ciência da educação? Portugal: Porto Editora, 1992.

FRANCO, M. A. Coordenação pedagógica: uma praxis em busca de sua identidade. Educativa, Goiânia, Revista do Departamento de Educação da UCG, v.8, n. I , p. I 25- | 38, jan./jul. 2005.

Pedagogia como ciência da educação. Campinas: Papirus, 2003.

A Pedagogia para além dos confrontos. In: FÓRUM DE EDUCAÇÃO: PEDAGOGO, QUE PROFISSIONAL É ESSE? 2003, Belo Horizonte. Anais do Fórum de Educação: pedagogo, que profissional é esse. Belo Horizonte: FAE/CBH/NEMG, $2003 \mathrm{~b}$. v. I, p.39-68.

A Práxis pedagógica como instrumento de transformação da prática docente. Anais da XXVIII ANPED. GTO4. Caxambu. 2005a. CD-ROM. 
Saberes pedagógicos e prática docente. Anais do XIII ENDIPE: Educação Formal e não formal, processos formativos e saberes pedagógicos. Recife: Bagaço, 2006. v. I, p.27-50.

HERBART, J. F. Pedagogia geral. Lisboa: Fundação Calouste Gulbenkian, 2003.

HOUSSAYE, J. (org.) Pédagogues contemporains. Paris: Armand Colin, 1995.

HOUSSAYE, J. et al. M. Manifeste pour les pédagogues. Paris: ESF Éditeur, 2002.

LIBÂNEO, José C. Adeus professor, adeus professora? São Paulo: Cortez, 1998.

Ainda as perguntas: o que é pedagogia, quem é o pedagogo, o que deve ser o curso de Pedagogia. In: PIMENTA, S. G. (org.) Pedagogia e pedagogos: caminhos e perspectivas. São Paulo: Cortez, 2002. p.59-97

Educação: pedagogia e didática - o campo investigativo da pedagogia e da didática no Brasil: esboço histórico e buscas de identidade epistemológica e profissional. In: PIMENTA, S. G. (org.) Didática e formação de professores. percursos e perspectivas no Brasil e em Portugal. São Paulo: Cortez, 1997. p.77-129.

Pedagogia e pedagogos, para quê? 8. ed. São Paulo: Cortez, 2005.

Pontos críticos dos atuais cursos de pedagogia. Presença Pedagógica, v. I I, n. 65, p.52-63, set./out.2005.

Sistema de ensino, escola, sala de aula: onde se produz a qualidade das aprendizagens? In: LOPES A. C.; MACEDO, E. (orgs.) Políticas de currículo em múltiplos contextos. São Paulo: Cortez, 2006. p. 70-125.

LIBÂNEO, J. C.; PIMENTA, S. G. Formação do profissionais da educação: visão crítica e perspectivas de mudança. Educação \& Sociedade, Campinas, v.20, n.68, p.239-77, 1999.

LUZURIAGA, L. História da educação e da pedagogia. São Paulo: Nacional, I97I.

MANACORDA, M. A. História da educação. São Paulo: Cortez; Campinas: Autores Associados, 1989.

MARQUES, M. O. A Formação do profissional de educação. ljuí: Ed. Unijuí, 1990.

MIALARET, G. As Ciências da educação. Lisboa: Moraes, 1976.

Pédagogie générale. Paris: Presses Universitaires de France, 1991.

PIMENTA, S. G. A Didática como mediação na construção da identidade do professor: uma experiência de ensino e pesquisa. In: ANDRÉ, M.; OLIVEIRA, M. R. (orgs.) Alternativas do ensino de didática. Campinas: Papirus, 1997. p.37-70. 
. Formação de professores: saberes da docência e identidade do professor. In: PIMENTA (org.) Saberes pedagógicos e atividade docente. São Paulo: Cortez, 1999. p. I 5-31 . . Para uma re-significação da didática: ciências da educação, pdagogia e didática (uma revisão conceitual e uma síntese provisória). In: PIMENTA, S. G. (org.) Didática e formação de professores. percursos e perspectivas no Brasil e em Portugal. São Paulo: Cortez, 1997a. p.19-76.

PIMENTA, S. G.; GHEDIN, E. (orgs.) Professor reflexivo no Brasil: gênese e crítica do conceito. São Paulo: Cortez, 2002.

QUINTANA CABANAS, J. M. Teoria de la educación: concepción antinómica de la educación. Madrid: Dykinson, 1995.

SARRAMONA, J.; MARQUES, S. Qué es la pedagogia? Una resposta atual. Barcelona: Ediciones CEAC, 1985.

SCHMIED-KOWARZIK, W. Pedagogia dialética. São Paulo: Brasiliense, 1983.

SILVA, C. S. B. da. Curso de pedagogia no Brasil: história e identidade. São Paulo: Autores Associados, 1999.

SÖETARD, M. Ciência(s) da educação ou sentido da educação? A saída pedagógica. In: HOUSSAYE, J. et al. Manifesto a favor dos pedagogos. Porto Alegre: Artmed, 2004. p.47-69.

VON CUBE, Félix. La Ciencia de la educación. Barcelona: Ediciones CEAC, 1981.

VISALBERGHI, A. Pedagogia e scienze dell'educazione. Milão: Arnoldo Mondadori Editore, 1983.

WILLMANN, OTTO. A Ciência da educação. Porto Alegre: Globo, 1970.

Recebido em: setembro 2006

Aprovado para publicação em: setembro 2006 